\title{
Study on Regional Economic Differences in China
}

\author{
Jinfeng $\mathrm{Xu}$, Caiyan She \\ Nanchang Institute of Science \& Technology, Nanchang, Jiangxi, 330008
}

Keywords: Regional Economic Differences, Chinese Economic Development, Develop Measures

\begin{abstract}
In the economic growth and social development, the economic development gap between countries or between regions and their development trends have aroused the interest of many scholars, and they have made a careful exploration and analysis of this issue. From the domestic literature point of view, some scholars have concluded that there is a convergence or conditional convergence between Chinese regional economies. However, these studies are based on the neoclassical growth structure model, assuming that the production sectors in the regional economies meet the homogeneity, and the convergence rates of these economies are monotonically attenuated by exponential rates. If the heterogeneity between the production sectors in the economy is allowed, the dynamic characteristics of the exponential decay contained in the neoclassical growth model may cease to exist, and the economic growth transfer dynamics will show a quantile decay or concussion decay process.
\end{abstract}

\section{Introduction}

In the global urbanization tide, China's urbanization has opened a new path of development, urbanization has caused structural efficiency, division of labor efficiency and scale efficiency, thus driving the economic growth, economic growth in turn accelerated the process of urbanization, towns And the economic growth between the two regions showed a synergistic effect, due to the distribution of population, capital and other resources between China, the level of urbanization and economic development level was uneven, also led to medical, education, social security and so on Equality, China's urbanization is in a major transition period, but how much is the degree of economic growth and the degree of urbanization? How to narrow the differences between urbanization and economic level in various regions and promote the process of urbanization in economically backward areas? The problem is the focus of the current discussion, which is related to the strategic planning of urbanization in China. By selecting the urbanization rate and per capita GDP of China in 1999-2015, this paper establishes the panel model for unit root test and co- To analyze the regional differences in urbanization rate and the relationship with economic growth.

\section{Differences in Regional Economic Cycles in China}

Based on the panel data of 30 provinces and cities in China from 1979 to 2008, this paper analyzes the economic growth spillover effect in the range of national sample data by constructing the neighboring level development variables and its subdivision variables, and the regional economic operation space The division problem. Through empirical analysis, we have come to the conclusion that the vast majority of the existing conclusions are very different, although the conclusions seem pessimistic, but still should cause our attention.

The export-oriented economic characteristics of the eastern part of China and the inward-oriented economic characteristics of the central and western regions are obvious. Although 
China's overall export-oriented economic characteristics are obvious, China's export-oriented economic characteristics are mainly caused by the rapid economic Expansion due.

The eastern and central and western regions only formed a one-way spillover effect, the economic growth in the central and western regions to promote economic growth in the east and the rapid growth of the East did not drive the economic growth in the central and western regions. The eastern part of the economic growth is based on the foreign market and not based on the domestic market, the eastern part of the foreign market has become part of the economic cycle of most of the nodes in the foreign market; the development of the central and western regions rely mainly on the local market and local resources, is strictly On the domestic market.

The middle and western regions have formed a benign two-way interaction pattern. Not only is the economic growth in the west promoted economic growth in the middle, the economic growth in the central region also promoted the economic growth in the west, and the two-way interaction between the central and western regions To a certain extent make up for the relatively backward development gap between the Midwest, but due to the lack of a strong eastern region of the strong spillover effect, the eastern and central and western development gap is still increasing.

The eastern and central and western regions of the formation of different oriented mutual economic cycle, is the impact of China's regional economic development of the fundamental reasons for the coordinated development.

\section{The Reasons for the Differences in Regional Economic Development in China}

The excessive reliance on foreign markets in the east can not achieve the goal of efficient allocation of resources and the use of foreign resources to promote economic growth in the east. However, once this path is formed, it will gradually alienate the domestic market because the organization of various production activities will depend on foreign countries Market demand and not take into account the domestic market, so from the foreign market import and export production-related technical equipment, from the Midwest to obtain and export production related to a variety of raw materials and labor. This result, the eastern and foreign markets to form a two-way interaction and the Midwest can only form one-way economic ties. Therefore, in this development strategy, the development of the eastern region to a greater extent led to the expansion of overseas markets, and did not drive the central and western regions of the relevant market development or expansion. Second, the low correlation between the eastern and central and western industrial activities further exacerbated the economic and circulatory system of the eastern and central and western regions. When the eastern part of the organization according to foreign markets to produce a variety of export products, if the central and western regions to provide the eastern part of the export production of various production factors, it is possible to form the eastern and central and western two-way interactive pattern, but the Midwest can not meet the eastern exit The eastern part of the market can only be found in the foreign market and export products to match the supply chain system, which formed the current eastern region more use of imported goods and inland areas more Use of the pattern of coastal products. Moreover, the inward-looking characteristics of the central and western economies also affect the formation of a large cycle of regional economic unity. In fact, China's reform and opening up process for nearly 30 years, is constantly accumulating the development of eastern coastal areas of the advantages of the process, the eastern region was the first opportunity in this development coupled with the eastern part of the original development base, the eastern region formed Continue to accumulate their own advantages of the cycle of accumulation process. China's central and western parts of the original foundation is quite weak, coupled with the state of the eastern coastal areas of the policy tilt, a large number of central and 
western elements to the east, the Midwest had to rely on local resources and local markets. Economic orientation must be inward rather than outward.

First of all, the eastern region of the economy should be dependent on foreign markets gradually transferred to the domestic market, that is, from the external demand gradually transferred to the domestic demand. At the beginning of the reform and opening up, taking a non-balanced development strategy, the conditions and prospects for the development of a good coastal areas tilt, is undoubtedly correct. However, from the perspective of regional coordinated development and urban and rural integration, it should be shifted from regional tilt to interregional coordination and urban and rural integration, which means that from the emphasis on external demand to focus on domestic demand, in the current global economic recession, China Economic development especially in the eastern coastal areas is an urgent need to shift to the domestic demand-driven path, because only in this way can we successfully achieve the industrial transformation of the eastern region, the central region of the industrial rise and industrial development in the western region. Second, we must improve the ability of the central and western regions to participate in the economic cycle. We should take effective measures to improve the relevance of the eastern and central and western industries, including the support of scientific research activities and scientific and technological talents in the central and western regions, to enhance the industries of the central and western regions and related industries in the eastern region (such as electrical machinery and manufacturing, Its communications equipment manufacturing industry, these industries have now become the pillar industry in the eastern region) supporting capacity to strengthen the construction of the transport capacity of the central and western regions. The local protectionists also artificially divide the market by setting up various trade barriers, thus affecting the spillover effect of the region. Therefore, to break the market segmentation problem is also imminent, and this need to further rationalize the relationship between the government at all levels, change the local government officials assessment system. In the direction of economic development, the central and western regions should not implement a unified export-oriented model, especially because the natural environment is relatively evil and do not have to attract foreign investment and large-scale economic construction conditions of the region, do not over-emphasize the development of export-oriented economy, These regions as a strategic reserve area for environmental protection and China's economic construction may be more strategic.

\section{Measures to Narrow Regional Economic Disparities}

In the real economy, no economy will adopt a balanced economic development strategy. In the face of differences in the process of economic development, there must be a clear understanding, not because of differences to give up the macroeconomic development strategy. From a macro point of view, the regional economic competition between the strong momentum, if a region does not have a strong economic growth pole, then in the process of competition with other regions will be at a disadvantage, not competition resources, the entire region The development will be more lagging behind. Face the difference, eliminate absolute poverty, control the serious polarization, the final economic differences will be like the inverted $U$ curve gradually narrowed. To make people get rich first step, the first rich after the rich, and ultimately achieve common prosperity. Zhengzhou and Luoyang is the Central Plains city group of two core, rather like dual-core CPU. Relying on the dual-core, the first Central Plains urban agglomeration to create a modern metropolitan area, so that Henan Province and other regions in competition will be in a favorable position in order to make full use of the province and outside the two resources, can better support backward areas development of. Kaifeng is the only one in the Central Plains city group in Henan Province in the 
backward level of the city. Therefore, we must increase the intensity of integration of Zheng and Kaifeng to prevent the emergence of short board effect.

There are two aspects of regional cooperation. First, Henan Province should strengthen economic cooperation with the eastern coastal areas, introduce the eastern part of the capital and advanced management experience, to encourage the developed areas of the saturated industry to the inland transfer. On the other hand, we should also pay attention to the cooperation within the region of Henan Province, the cooperation between the cities. Local governments' regional economic cooperation plays a vital role in promoting the coordinated development of regional economy and constructing a coordinated and orderly economic zone. Decision-makers should be guided by the policy, so that between the various cities to achieve complementary advantages, benefit-sharing, in order to achieve the purpose of common development.

\section{Conclusion}

After the reform and opening up, from the Pearl River Delta to the Yangtze River Delta and then to the development and opening up the Bohai Sea, China's eastern coastal areas of the economy has made considerable progress, but the vast central and western regions of the economic development is very slow. To this end, the state launched a series of macroeconomic plans aimed at coordinating regional economic development. The free flow of elements among regions is an important way to promote regional coordinated development. The elimination of local protectionism by various cities and municipalities should eliminate the system and the barriers of the regional flow of elements, increase the degree of openness between regions, and optimize the allocation and rational flow of elements under the regulation of market price mechanism.

\section{References}

[1] Guo Haihua, Xia Zhijun, Zhou Yuan. Empirical Study on the Relationship between Energy Consumption and Economic Growth in China [J]. China Market, 2010 (45)

[2] Tu Yingjiu, Xing Hongbo. Analysis of the Effect of Energy on Economic Development in Jiangxi Province [J] .Energy Resources Research and Management, 2010 (03)

[3] Song Meizhe, Cai Xiaochun. Statistical Test of the Relationship between Economic Growth Quality and Energy Consumption in China [J]. Journal of Statistics and Decision, 2010 (14)

[4] Wang Yuan, Zhou Jing. Cointegration Analysis of Resource Consumption and Economic Growth in Jiangsu Province [J]. Chinese Journal of Population and Environment, 2010 (06)

[5] Qin Jing, Niu Shuwen. Empirical Study on Energy Consumption and Economic Growth in Gansu Province [J]. Journal of Regional Studies and Development, 2010 (03)

[6] Ningze Kui. Energy consumption and economic growth cointegration analysis: based on macro data comparison analysis [J]. Statistics and Information Forum, 2010 (03) 